\title{
Probabilistic evaluation of climate change impacts on paddy rice productivity in Japan
}

\author{
Toshichika Iizumi • Masayuki Yokozawa • \\ Motoki Nishimori
}

Received: 30 April 2009 / Accepted: 29 September 2010 / Published online: 16 December 2010

(C) The Author(s) 2010. This article is published with open access at Springerlink.com

\begin{abstract}
Projecting the impacts of climate change includes various uncertainties from physical, biophysical, and socioeconomic processes. Providing a more comprehensive impact projection that better represents the uncertainties is a priority research issue. We used an ensemble-based projection approach that accounts for the uncertainties in climate projections associated with general circulation models (GCMs) and biophysical and empirical parameter values in a crop model. We applied the approach to address the paddy rice yield change in Japan in the 2050s (2046-2065) and 2090s (2081-2100) relative to the 1990s (1981-2000). Seventeen climate projections, nine (eight) climate projections performed by seven (six) GCMs conditional on the Special Report on Emission Scenarios (SRES) A1B (A2), were included in this projection. In addition, 50 sets of biophysical and empirical parameter values of a large-scale process-based crop model for irrigated paddy rice were included to represent the uncertainties of crop parameter values. The planting windows, cultivation practices, and crop cultivars in the future were assumed to be the same as the level in the baseline period (1990s). The resulting probability density functions conditioned on SRES A1B and A2 indicate projected median yield changes of $+17.2 \%$ and $+26.9 \%$ in Hokkaido, the northern part of Japan, in the 2050 s and 2090 s with $90 \%$ probability intervals of $(-5.2 \%,+40.3 \%)$ and $(+6.3 \%$, $+51.2 \%$ ), relative to the 1990 s mean yield, respectively. The corresponding values in Aichi, on the Pacific side of Western Japan, are $2.2 \%$ and $-0.8 \%$, with $90 \%$ probability intervals of $(-15.0 \%,+14.9 \%)$ and $(-33.4 \%,+17.9 \%)$, respectively. We also provided geographical maps of the probability that the future 20-year mean yield will decrease and that the future standard deviation of yield for 20 years will
\end{abstract}

T. Iizumi · M. Yokozawa · M. Nishimori

National Institute for Agro-Environmental Sciences, 3-1-3 Kannondai, Tsukuba, Ibaraki 305-8604, Japan

T. Iizumi $(\bowtie)$

Agro-meteorology Division, National Institute for Agro-Environmental Sciences, 3-1-3 Kannondai, Tsukuba, Ibaraki 305-8604, Japan e-mail: iizumit@affrc.go.jp 
increase. Finally, we investigated the relative contributions of the climate projection and crop parameter values to the uncertainty in projecting yield change in the 2090s. The choice of GCM yielded a relatively larger spread of projected yield changes than that of the other factors. The choice of crop parameter values could be more important than that of GCM in a specific prefecture.

\section{Introduction}

Climate change during the last few decades has been affecting crop growth, development, and productivity in broad regions of the world (Easterling et al. 2007). Future climate change has the potential to bring further negative impacts on crops and is, therefore, a major concern in terms of food security and regional agricultural production. Extensive studies have projected the potential impacts of future climate change on agricultural productivity on the basis of crop models with climate change scenarios derived from general circulation models (GCMs) to assess the climate risks in global and regional scales (e.g., Parry et al. 2004; Challinor et al. 2005; Tao et al. 2008, 2009b; Iizumi et al. 2006, 2007, 2008).

However, projecting climate change impacts includes large uncertainties from various sources, such as imperfect modeling and ignorance of socioeconomic, physical, and biophysical processes (Katz 2002; Carter et al. 2007; Lobell and Burke 2008). Major uncertainties in projecting the impacts of climate change on agricultural productivity are mainly originated from greenhouse gas emission scenarios, especially for carbon dioxide $\left(\mathrm{CO}_{2}\right)$, climate projections performed by GCMs, and parameterized biophysical processes of crop models. The treatment of these uncertainties has been steadily improved by the results of climate modeling studies (e.g., Murphy et al. 2004; Meehl et al. 2007b) and impact studies (e.g., Challinor et al. 2005; Challinor and Wheeler 2008; Lobell and Burke 2008; Tao et al. 2009b); however, providing a more comprehensive impact projection that better represents the uncertainties is still a priority research issue.

Reflecting the increasing recognition of uncertainties in projecting the impacts, recent studies have shown improvements in the technique used for dealing with these uncertainties. Tao et al. (2008) indicated the probability of future rice yield change in China using many climate scenarios generated by a Monte Carlo simulation technique. Challinor et al. (2009) estimated the uncertainties in simulating the groundnut yield in India associated with the combinations of biophysical parameter values in a crop model and physical parameter values in a GCM. Iizumi et al. (2009) systematically inferred the probability distributions of biophysical and empirical parameter values in a crop model by using a Bayesian inversion analysis and quantified the uncertainty in simulating paddy rice yield in Japan under current climate associated with these parameter values. Tao et al. (2009b) demonstrated the probability of maize yield changes in northern China using a super-ensemblebased probabilistic projection approach considering many combinations of emission scenarios, climate projections, and biophysical parameter values in a crop model.

As a continuation of previous studies (Iizumi et al. 2009), we aimed (1) to provide an ensemble-based projection of paddy rice yield changes in Japan in the 2050s (2046-2065) and 2090s (2081-2100) that accounts for not only the uncertainty of crop parameter values in the crop model but also uncertainties of climate projections un- 

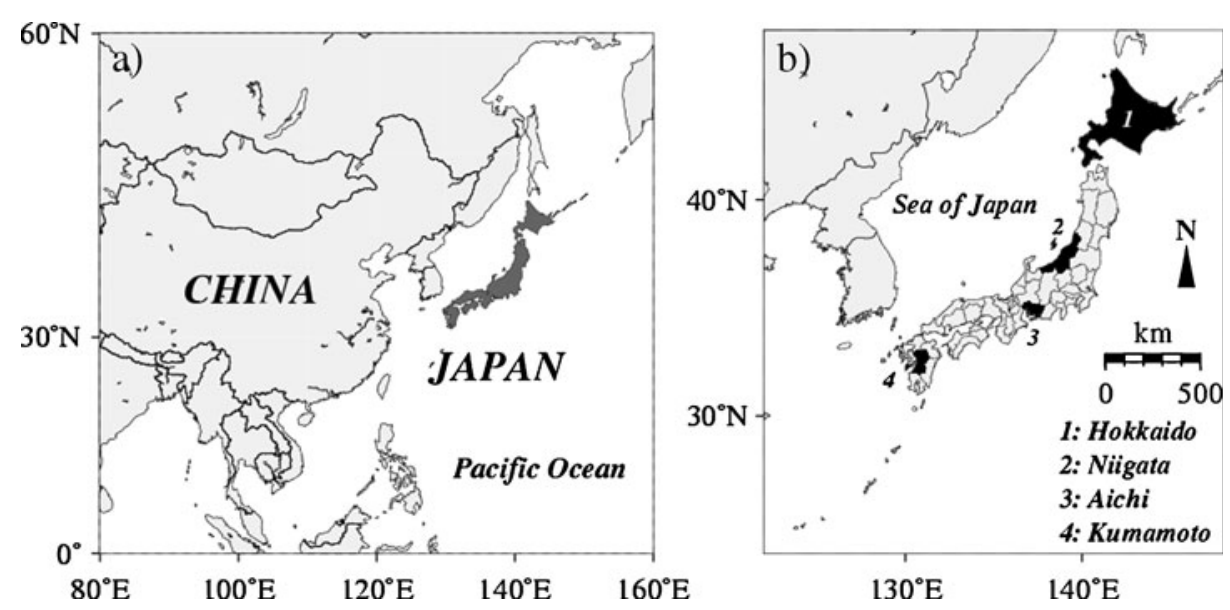

Fig. 1 Geographical location of Japan (a), distribution of 47 prefectures in Japan and four selected representative prefectures (b). (1) Hokkaido, in the northern part of Japan, (2) Niigata, in the Sea of Japan side of the eastern part of Japan, (3) Aichi in the Pacific side of the central part of Japan, and (4) Kumamoto in the western part of Japan (b)

der the two emission scenarios; and (2) to provide probability maps of climate change impacts on paddy rice yield in the whole of Japan on a local government level (called prefecture). Of 47 prefectures in Japan, we selected some representative prefectures to infer the impacts of climate change on paddy rice under various climate conditions in Japan. Here, we selected the candidate prefectures for each of the roughly divided climate zones in Japan, e.g., the northern part of Japan, the western part of Japan, the Pacific side, and the Sea of Japan side. We examined the paddy rice acreage of the candidates and rejected the prefectures with smaller acreage. We further rejected candidates on the basis of the reproductive capability of the crop model used in this study (see Section 3.1). Finally, we referred to the agroecological zones in Japan (Horie et al. 1995b) and selected the four representative prefectures to investigate the areal differences: (1) Hokkaido, in the northern part of Japan; (2) Niigata, in the Sea of Japan side of the eastern part of Japan; (3) Aichi, in the Pacific side of the central part of Japan; and (4) Kumamoto, in the western part of Japan (Fig. 1). These prefectures are major or fairly primary sources of paddy rice in Japan and belong to different climate and agroecological zones.

\section{Materials and methods}

\subsection{Large-scale crop model for irrigated paddy rice}

We applied the Process-based Regional-scale Rice Yield Simulator with Bayesian Inference (PRYSBI) (Iizumi et al. 2009; Yokozawa et al. 2009) for this study. Details of the model development, parameter optimization, and sensitivity analysis are available from Iizumi et al. (2009). The PRYSBI model is upscaled from a fieldscale crop model SIMRIW (Horie et al. 1995a) through a Bayesian inversion analysis with the concept that the crop parameter values of the PRYSBI model distributed 
in a probabilistic manner to express the spatial heterogeneity of rice crop responses to local climate conditions and crop production aspects (e.g., planting window and cultivar) in a prefecture. Management factors (e.g., irrigation, fertilization, and pest control) are not explicitly accounted for in a process-based manner and are expressed as the yield gap parameter. The yield gap parameter value approaches unity if the rice crop is well managed and zero if the actual rice yield is far less than the potential value. In the PRYSBI model, the yield gap parameter values are also expressed as a probabilistic distribution. By this analysis, we determined the posterior distribution of crop parameter values conditioned on given phenological and yield data on a prefectural scale. The PRYSBI model thereby simulates paddy rice yields in a given prefecture with various sets of 13 parameter values (Table 1) sampled from the corresponding posterior distributions of crop parameter values and area-averaged daily weather inputs. In that sense, the PRYSBI model is a large-scale crop model and has the advantage to simulate the typical yield and range of yields on a large scale in contrast to the field-scale crop model, which has a single set of crop parameter values.

The calibration and verification procedures of the PRYSBI model were the same as those in Iizumi et al. (2009). Briefly, for each prefecture, the posterior distribution of each parameter value was estimated by the Markov Chain Monte

Table 1 Mean, standard deviation (SD), and 90\% (5-95\%) interval of 50 sets of crop parameter values used in this study

\begin{tabular}{|c|c|c|c|c|}
\hline$\overline{\text { Parameter (unit) }}$ & Mean & SD & $90 \%$ interval & Definition \\
\hline \multicolumn{5}{|c|}{ Initial condition parameters } \\
\hline$D V I_{0}\left(\right.$ day $\left.^{-1}\right)$ & 0.099 & 0.024 & $(0.056,0.135)$ & Initial developmental index (DVI) \\
\hline$L A I_{0}\left(\mathrm{~m}^{2} \mathrm{~m}^{-2}\right)$ & 0.048 & 0.014 & $(0.028,0.067)$ & Initial leaf area index \\
\hline$D W_{0}\left(\mathrm{~g} \mathrm{~m}^{-2}\right)$ & 3.022 & 0.799 & $(1.696,4.386)$ & Initial dry weight \\
\hline \multicolumn{5}{|c|}{ Phenological and developmental parameters } \\
\hline$G$ (day) & 64.904 & 11.907 & $(43.96,75.508)$ & $\begin{array}{l}\text { Minimum number of days required } \\
\text { for heading under } 350 \mathrm{ppm} \text { of } \\
\text { atmospheric } \mathrm{CO}_{2} \text { concentration }\end{array}$ \\
\hline$A_{T}(-)$ & 0.285 & 0.091 & $(0.192,0.479)$ & $\begin{array}{l}\text { Sensitivity of developmental rate } \\
\text { (DVR) to air temperature }\end{array}$ \\
\hline$T_{h}\left({ }^{\circ} \mathrm{C}\right)$ & 17.640 & 1.701 & $(15.557,20.388)$ & $\begin{array}{l}\text { Air temperature at which DVR is } \\
\text { half of the maximum rate at the } \\
\text { optimum temperature }\end{array}$ \\
\hline$B_{L}(-)$ & 0.627 & 0.187 & $(0.365,0.962)$ & Sensitivity of DVR to day length \\
\hline$L_{c}(\mathrm{~h})$ & 23.315 & 6.401 & $(12.792,33.759)$ & Critical day length \\
\hline$D V I^{*}\left(\right.$ day $\left.^{-1}\right)$ & 1.093 & 0.264 & $(0.654,1.457)$ & $\begin{array}{l}\text { Value of DVI at which point the } \\
\text { crop becomes sensitive to the } \\
\text { photoperiod }\end{array}$ \\
\hline \multicolumn{5}{|c|}{ Yield formation parameters } \\
\hline$T^{*}\left({ }^{\circ} \mathrm{C}\right)$ & 20.440 & 4.523 & $(13.496,27.796)$ & $\begin{array}{l}\text { Base air temperature for calculating } \\
\text { cooling degree days }\end{array}$ \\
\hline$C_{\text {cool }}(-)$ & 1.461 & 0.392 & $(0.781,2.152)$ & $\begin{array}{l}\text { Curvature factor of spikelet sterility } \\
\text { caused by low temperature }\end{array}$ \\
\hline$C_{h o t}(-)$ & 15.555 & 4.387 & $(8.582,21.791)$ & $\begin{array}{l}\text { Curvature factor of spikelet sterility } \\
\text { caused by high temperature }\end{array}$ \\
\hline$\tau(-)$ & 0.646 & 0.230 & $(0.425,1.101)$ & Yield gap parameter \\
\hline
\end{tabular}


Carlo (MCMC) technique (Geman et al. 1993) on the basis of the error information between the simulated heading date and yield with observed weather inputs and the corresponding observed ones during 13 odd years from 1979 to 2003 (i.e., 1979, 1981, .., 2001, and 2003): this is the calibration procedure. The PRYSBI model was verified by comparing the simulated yield and the corresponding observed yield during the 20 years (1981-2000) including independent 10-even-year data.

For this study, we selected 50 sets of crop parameter values for each prefecture that have smaller root-mean-square error (RMSE) from 3,000 sets of crop parameter values sampled from the posterior distributions. The RMSE was calculated from the 20-year (1981-2000) data. These sets of parameter values were common throughout all simulations. Figure 4 shows the range of the selected 50 sets of crop parameter values. With reference to Horie et al. (1995a) and Nakagawa et al. (2003), the parameter values of a specific cultivar that is popular in each of the representative prefectures are also shown (i.e., Ishikari for Hokkaido, Koshihikari for Niigata, Nipponbare for Aichi, and Mizuho for Kumamoto). The statistics of the range of parameter values are summarized in Table 1 . The median values of the 13 parameters clearly vary by prefecture and are close to the reported parameter values for the corresponding cultivar, suggesting that the sampled parameter values adequately represent the biophysical characteristics of the planted cultivar in each prefecture. The initial conditions of the rice crop at transplanting are within the range of reported values (Fig. 2a, b, and c), although the median values of the initial dry weight $\left(D W_{0}\right)$ tend to be smaller. The spatial differences in median values are similar to those of specific cultivars. For instance, the number of days required for heading $(G)$, sensitivity of the developmental rate (DVR) to temperature $\left(A_{T}\right)$, and temperature at which DVR is half of the maximum rate $\left(T_{h}\right)$ in Hokkaido and Niigata are smaller than those in the other prefectures. Such a tendency is roughly expressed in the median values of the selected 50 sets (Fig. 2d, e, and f). Ishikari is insensitive to day length compared to other three cultivars. This tendency appeared in the median values of the critical day length $\left(L_{c}\right)$ (Fig. $2 \mathrm{~h}$ ). For the other parameter values, the median varies around the reported values for a specific cultivar $\left(T^{*}\right.$ and $\left.C_{\text {cool }}\right)$ or, at least, includes the reported values $\left(C_{h o t}\right)$. The yield gap parameter $(\tau)$ in the northern part of Japan (e.g., Hokkaido) is greater than that in the western part of Japan (e.g., Kumamoto) (Fig. 2m). This tendency is the same as the result reported in Iizumi et al. (2009).

\subsection{Data}

The PRYSBI model requires daily inputs of daily maximum and minimum temperatures, daily total solar radiation, and annual input of atmospheric $\mathrm{CO}_{2}$ concentration. Precipitation, vapor pressure, and soil moisture are not used because the irrigation system is prevalent in the whole of Japan. These conditions are thus not key factors for the variation of paddy rice yield in Japan. This premise was common for the future, considering that many climate projections indicate an increase in the warm season precipitation around Japan (Kimoto et al. 2005; Kurihara et al. 2005; Meehl et al. 2007a). We provided the daily time-series data of temperature and radiation during the 25 years (1979-2003), averaging mesh values on the paddy fields obtained from the Mesh-Automated Meteorological Data Acquisition System (Mesh-AMeDAS) data (Seino 1993), which has a spatial distribution of $1 \times 1 \mathrm{~km}$. 

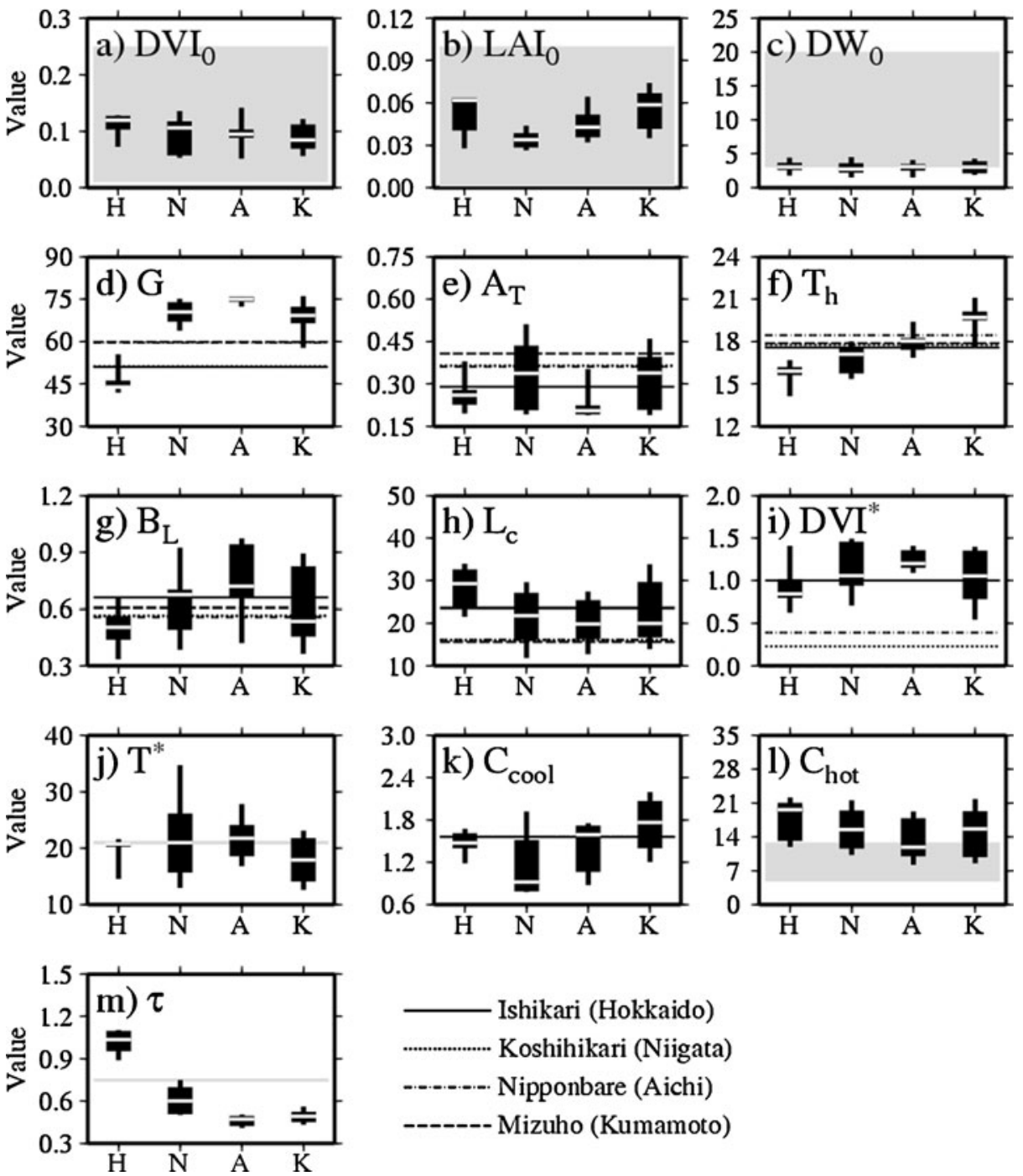

Fig. 2 Box plots of 50 sets of crop model parameter values for Hokkaido $(H)$, Niigata $(N)$, Aichi $(A)$, and Kumamoto $(K)$ used in this study. The vertical line indicates the range between the $5 \%$ and $95 \%$-tile value. The upper and lower hinge of a box indicates the $75 \%$ - and $25 \%$-tile value, respectively. The white line in a box indicates the median value. The crop parameter values of a popular cultivar in each of four prefectures (from Horie et al. 1995b; Nakagawa et al. 2003) are shown as a reference. The gray shaded area indicates the range of parameter values from the literature but not for a specific cultivar

The meshes of paddy fields were extracted using digital numerical land information (GSI 1998), which is a land-use/land-cover map in Japan with the same spatial resolution as that of the Mesh-AMeDAS data.

Seventeen climate projections over Japan with daily temporal resolution and $10 \times 10 \mathrm{~km}$ spatial resolution during the two 20-year periods (2046-2065 and 20812100) were obtained from Okada et al. (2009). Table 2 summarizes 17 climate 
Table 2 List of GCMs, global surface warming in the 2050s and 2090s (relative to the 1990s) and spatial resolutions

\begin{tabular}{|c|c|c|c|c|c|}
\hline \multirow[t]{3}{*}{ GCM } & \multicolumn{4}{|c|}{ Surface global warming } & \multirow[t]{3}{*}{ Spatial resolution } \\
\hline & \multicolumn{2}{|l|}{$\overline{\mathrm{A} 1 \mathrm{~B}}$} & \multicolumn{2}{|l|}{$\mathrm{A} 2$} & \\
\hline & $2050 \mathrm{~s}$ & $2090 \mathrm{~s}$ & $2050 \mathrm{~s}$ & $2090 \mathrm{~s}$ & \\
\hline$\overline{\text { CGCM3.1 (1) }}$ & 1.6 & 2.4 & 1.7 & 3.2 & $3.8^{\circ} \times 3.8^{\circ}$ \\
\hline CGCM3.1 (2) & 1.6 & 2.4 & 1.8 & 3.3 & $3.8^{\circ} \times 3.8^{\circ}$ \\
\hline CGCM3.1 (3) & 1.7 & 2.4 & 1.8 & 3.3 & $3.8^{\circ} \times 3.8^{\circ}$ \\
\hline CSIRO-Mk3.0 & 1.0 & 1.8 & 1.2 & 2.6 & $1.9^{\circ} \times 1.9^{\circ}$ \\
\hline CSIRO-Mk3.5 & 1.8 & 3.0 & 1.9 & 3.5 & $1.9^{\circ} \times 1.9^{\circ}$ \\
\hline GFDL-CM2.0 & 2.0 & 3.1 & 1.9 & 3.4 & $2.5^{\circ} \times 2.0^{\circ}$ \\
\hline MIROC3.2-MEDRES & 1.9 & 3.2 & 1.8 & 3.6 & $2.8^{\circ} \times 2.8^{\circ}$ \\
\hline MIROC3.2-HIRES & 2.7 & 2.2 & n.a. & n.a & $1.1^{\circ} \times 1.1^{\circ}$ \\
\hline MRI-CGCM2.3.2A & 1.4 & 4.1 & 1.3 & 2.5 & $2.8^{\circ} \times 2.8^{\circ}$ \\
\hline
\end{tabular}

CGCM3.1 has three ensemble members with different initial conditions

projections, nine (eight) climate projections performed by seven (six) GCMs under the Special Report on Emission Scenarios (SRES) (Nakicenovic and Swart 2000) A1B (A2) scenario. Three ensemble members with different initial conditions were available only for CGCM3.1. For each climate projection, we simply corrected the climate-model bias of the interpolated daily data in terms of the mean and standard deviation during the 20 years using simulated and observed data in the baseline period (1981-2000). In practice, for each of the three climatic elements, a biascorrected daily climatic element for 20 years, $\mathrm{X}_{\mathrm{Cor}}$, was computed on a daily time scale:

$$
\mathrm{X}_{\mathrm{Cor}}=\left\langle\mathrm{X}_{\mathrm{Obs}}\right\rangle+\frac{\sigma\left(\mathrm{X}_{\mathrm{Obsi}}\right)}{\sigma\left(\mathrm{X}_{\mathrm{CMi}}\right)}\left(\mathrm{X}_{\mathrm{CM}}-\left\langle\mathrm{X}_{\mathrm{CM}}\right\rangle\right),
$$

where $\mathrm{X}_{\mathrm{Obs}}$ and $\mathrm{X}_{\mathrm{CM}}$ were the daily time series of the climatic element of observed and simulated data, respectively. $\sigma(\cdot)$ denotes the standard deviation of the climatic element in parentheses in the $i$ th month calculated from daily data for 20 years, and $<$. $>$ indicates the daily time series of the 20-year climatological mean of the climatic element in brackets. This bias correction technique sometimes provided unrealistic daily total solar radiation values, for instance, a zero and a value so large that it was beyond the value at the top of the atmosphere. In that case, we simply replaced the unrealistically large value with the maximum value of the observed data in the corresponding month. An unrealistically small value is treated in the same manner but is replaced with the minimum value of observed data.

Annual data of the atmospheric $\mathrm{CO}_{2}$ concentration were obtained from the World Data Center for Greenhouse Gases (http://gaw.kishou.go.jp/wdcgg/). After obtaining the data observed at the Ryori site $\left(39.03^{\circ} \mathrm{N}, 141.82^{\circ} \mathrm{E}\right)$ in Japan during the 24 years (1984-2007), unobserved data from 1981 to 1983 were estimated, extrapolating a temporal linear regression curve calculated from all of the available data. Any error associated with this extrapolation would be small for a crop yield simulation because the annual rate of increase in the $\mathrm{CO}_{2}$ concentration did not vary significantly for this period. One value was used annually for all prefectures in crop model simulations. On the other hand, two future scenarios of $\mathrm{CO}_{2}$ emission and expected atmospheric $\mathrm{CO}_{2}$ concentration were obtained from the SRES A1B and A2. Annual data during 
the two 20-year periods (2046-2065 and 2081-2100) were estimated using a temporal linear regression curve calculated from available decadal data during 2000-2100.

For 47 prefectures, annual paddy rice yield and crop calendar data (i.e., transplanting, heading, and harvesting dates) on a prefectural level during 1979-2003 were obtained from the annual report on crop statistics provided by the Ministry of Agriculture, Forestry, and Fisheries, Japan (MAFF). Yield trend data estimated by a non-parametric regression method with the assumption of normal weather (MAFF 1998) are also available from the annual reports. The yield trend was removed from the actual yield to focus on the climate-crop relationship. The detrended yield data were referred to as the "observed yield" and used in the calibration and verification of the PRYSBI model.

\subsection{Ensemble-based projection approach}

Iizumi et al. (2009) conducted the PRYSBI model simulations with daily inputs of current climatology and 5,000 sets of parameter values inferred by the MCMC technique and then provided a cumulative probability density function (CDF) of simulated paddy rice yields. These CDFs indicate the uncertainty in simulating paddy rice yield associated with crop parameter values. In this study, we further extended this concept and applied 17 climate projections conditional on two emission scenarios (A1B and A2).

Using the selected 50 sets of crop parameter values (see Section 2.1), we conducted the PRYSBI model simulations with the observed weather inputs under current climate conditions and bias-corrected 17 climate projections in the middle and end of this century. We calculated the mean yield in the current 20-year period (19812000 , referred to as the 1990s) for each prefecture and future yield changes, relative to the mean yield in the 1990s, during the two 20-year periods (2045-2065 and 20812100 , referred to as the 2050s and 2090s, respectively): this yielded an ensemblebased projection of paddy rice yield changes. We provided the probability density functions (PDFs) and the corresponding CDFs of paddy rice yield changes for each prefecture from the large number of simulation results.

\section{Results}

\subsection{Crop model verification}

For each prefecture, the ensemble mean of simulated yields in the 1990s with observed daily weather inputs was verified in terms of the Pearson's correlation coefficient $(r)$ and RMSE on the basis of the corresponding observed yield. Figure 3 indicates the geographical distributions of the correlation coefficient and RMSE. Of 47 prefectures, the number of prefectures was 4 for $r<0.3 ; 21$ for $0.3 \leq r<0.6$; and 22 for $0.6 \leq r$. The correlation is statistically significant at the $5 \%$ level in the 37/47 prefectures. On the other hand, the number of prefectures was 33 for $0.2 \leq \mathrm{RMSE}<0.4$; 13 for $0.4 \leq \mathrm{RMSE}<0.6$; and 1 for $0.6 \leq \mathrm{RMSE}$ in units of $\mathrm{Mg}$ $\mathrm{ha}^{-1}$.

Figure 4 shows the time-series of the 50 ensemble members and the ensemble mean of simulated yields with observed daily weather inputs and the corresponding 


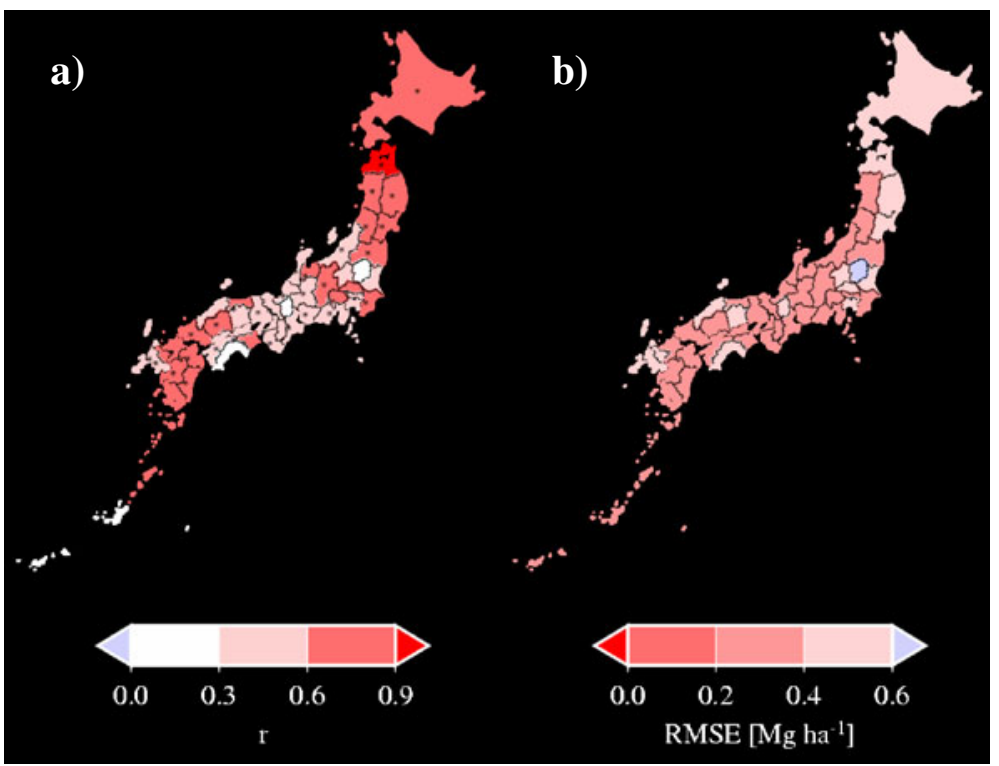

Fig. 3 Geographical distribution of the Pearson's correlation coefficient (a) and root-mean square error (b) for each prefecture calculated between the simulated yield with observed weather inputs and the corresponding observed yield in the 1990s. The asterisk indicates that the correlation coefficient is statistically significant at the $5 \%$ level

observed yield in the 1990s for the representative prefectures. The correlation and RMSE between the ensemble mean of simulated yields and the corresponding observed yield were $0.865\left(p=0.000^{*}\right)$ and $0.412 \mathrm{Mg} \mathrm{ha}^{-1}$ for Hokkaido, respectively; $0.564\left(p=0.010^{*}\right)$ and $0.303 \mathrm{Mg} \mathrm{ha}^{-1}$ for Niigata, respectively; $0.453\left(p=0.045^{*}\right)$ and $0.281 \mathrm{Mg} \mathrm{ha}^{-1}$ for Aichi, respectively; and $0.829\left(p=0.000^{*}\right)$ and $0.256 \mathrm{Mg} \mathrm{ha}^{-1}$ for Kumamoto, respectively. All correlation values for the representative prefectures are statistically significant at the 5\% level.

The PRYSBI model with observed daily weather inputs could reasonably simulate the paddy rice yield of the prefectural average in most prefectures. In the four representative prefectures, each ensemble member of simulated yield showed a close value to the corresponding observed yield with difference among members (Fig. 4), resulting in nonlinear responses of crop dynamics (biophysical parameter values) to climate conditions. These results suggest that the PRYSBI model correctly captured the major characteristics of the interannual variation of paddy rice yield derived from climate variation with the inclusion of spatial heterogeneity of crop production aspects in a prefecture. This would increase the reliability of the projected yield changes in terms of the mean productivity and interannual variation of yield.

\subsection{Probabilities of yield changes and extremely hot days}

Figures 5 and 6 present the PDFs and CDFs of growing period changes and yield changes of paddy rice in the 2050s and 2090s, relative to the 1990s mean value, for Hokkaido, Niigata, Aichi, and Kumamoto, respectively. Each of the PDF (CDF) 

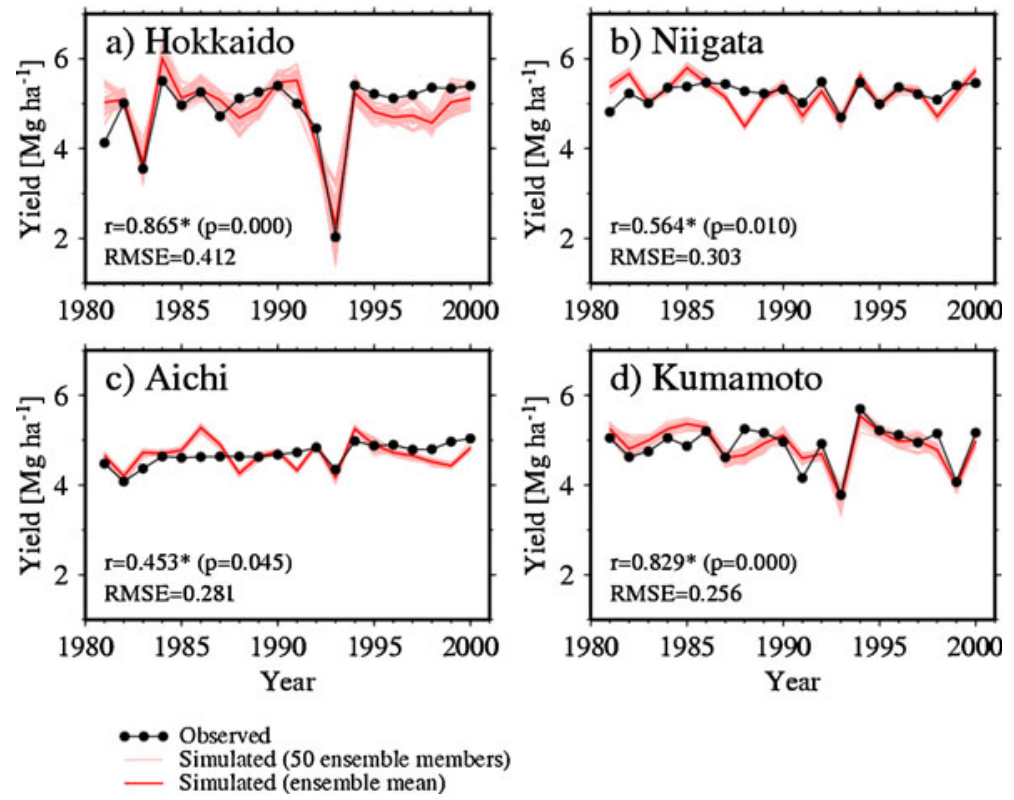

Fig. 4 Time series of the observed yield, 50 ensemble members of the simulated yield, and ensemble mean for four representative prefectures. The asterisk indicates that the correlation coefficient is statistically significant at the $5 \%$ level

was made from the 17,000 simulation results ( $=17$ climate projections based on 2 scenarios $\times 50$ sets of parameters $\times 20$ years). All PDFs for growing period changes and yield changes showed a general Gaussian form with slight negative skewness. The degree of skewness varied with the prefecture and time.

The peak of the PDFs for growing period changes shifted more to the negative side over time in all four prefectures, indicating the shortening of the growing period (Fig. 5). The resulting CDF showed the projected growing period change of -9.9 days and -15.6 days in the median value for Hokkaido in the 2050s and 2090s with $90 \%$ probability intervals of ( -19.2 days, -3.0 days) and $(-23.8$ days, -8.9 days), relative to the 1990s mean growing period, respectively (Fig. 5a). The corresponding values were -10.1 days and -15.6 days with $90 \%$ probability intervals of ( -17.8 days, -4.4 days) and (-23.6 days, -9.7 days) for Niigata, respectively (Fig. $5 b) ;-8.0$ days and -12.1 days with $90 \%$ probability intervals of $(-12.4$ days, -4.1 days) and ( -16.5 days, -8.3 days) for Aichi, respectively (Fig. 5c); and -8.2 days and -12.5 days with $90 \%$ probability intervals of ( -13.0 days, -4.6 days $)$ and ( -17.6 days, -8.0 days) for Kumamoto, respectively (Fig. $5 \mathrm{~d})$.

The peak of the PDFs for yield changes shifted more to the positive side over time in all four prefectures, indicating the yield increase (Fig. 6). The standard deviation (SD) of the PDFs became larger over time in Aichi and Kumamoto, whereas it seemed to remain at almost the same level as that in the 1990s in Hokkaido and Niigata. The tail of the PDFs in the negative side extended to a more negatively strong side in Aichi and Kumamoto, whereas such an extension was not found in the other two prefectures. Table 3 summarizes the statistics of the CDFs for the yield 

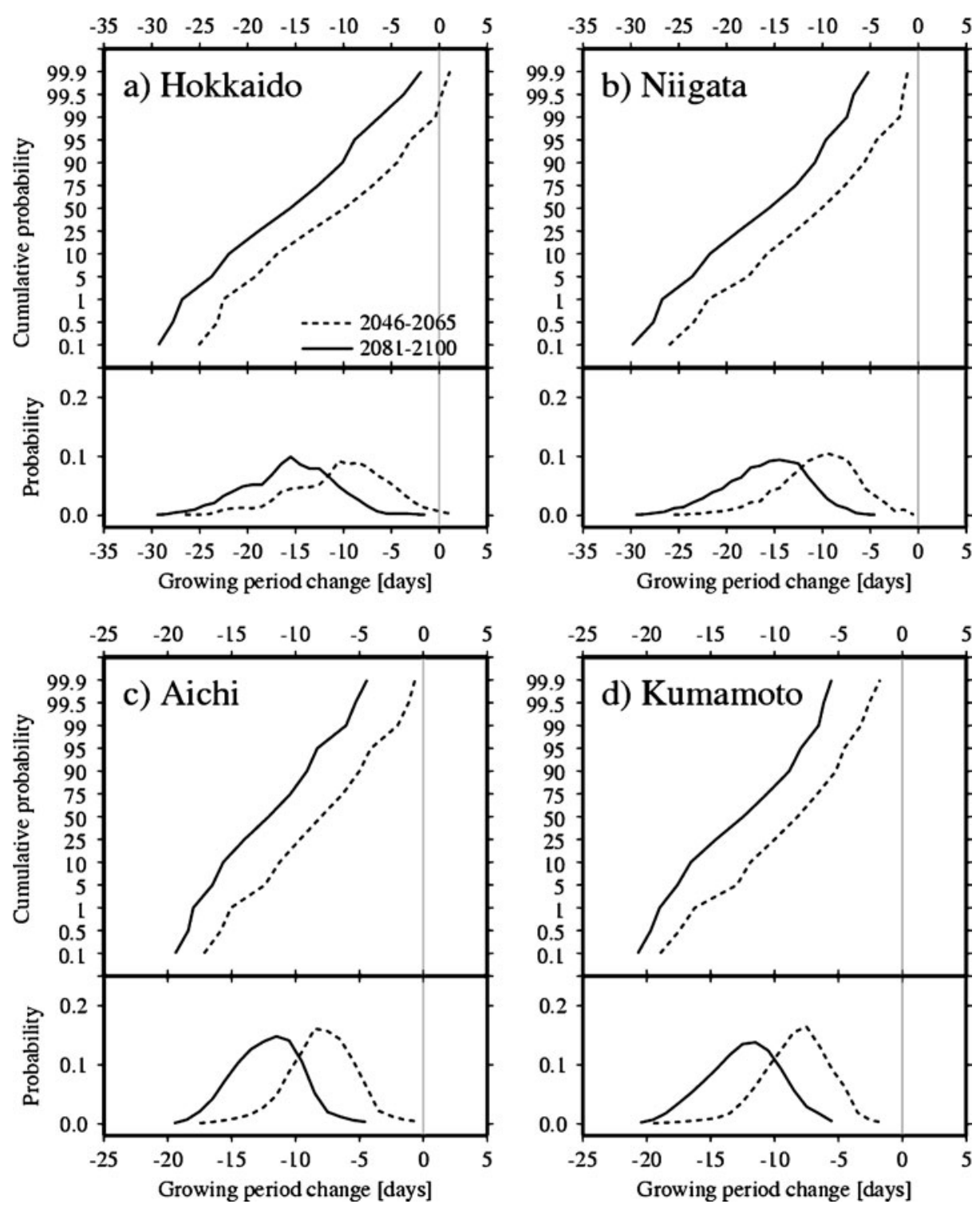

Fig. 5 Cumulative probability density functions of growing period changes in the 2050s and 2090s, relative to the 1990 s, for four representative prefectures

changes presented in Fig. 6. The resulting CDF showed the projected mean yield change of $+17.2 \%$ and $+26.9 \%$ for Hokkaido in the 2050 s and 2090 s with $90 \%(5 \%$ to $95 \%)$ probability intervals of $(-5.2 \%,+40.3 \%)$ and $(+6.3 \%,+51.2 \%)$, relative to the 1990 s mean yield, respectively (Fig. 6a). The corresponding values were $4.6 \%$ and $+7.4 \%$ with $90 \%$ probability intervals of $(-9.4 \%,+17.3 \%)$ and $(-5.8 \%,+22.0 \%)$ for Niigata, respectively (Fig. $6 b) ;+2.2 \%$ and $-0.8 \%$ with $90 \%$ probability intervals 

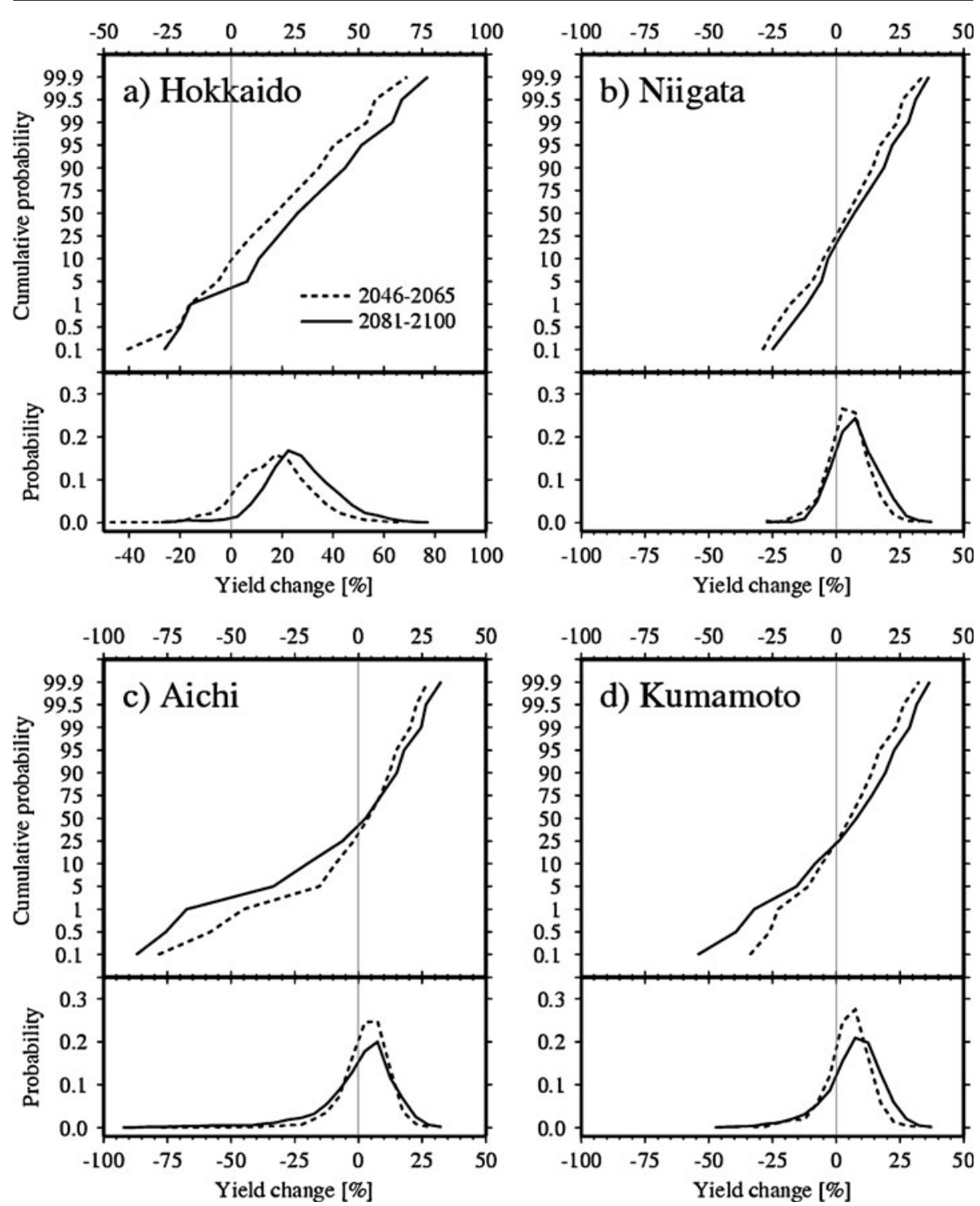

Fig. 6 Same as Fig. 5 but for yield changes

of $(-15.0 \%,+14.9 \%)$ and $(-33.4 \%,+17.9 \%)$ for Aichi, respectively (Fig. 6c); and $+4.6 \%$ and $+6.4 \%$ with $90 \%$ probability intervals of $(-10.9 \%,+17.0 \%)$ and $(-15.6 \%,+22.8 \%)$ for Kumamoto, respectively (Fig. 6d).

Figure 7 shows the normalized histograms of extremely hot days (daily maximum temperature during a heading period, $\mathrm{T}_{\max } \geq 33^{\circ} \mathrm{C}$ ) in the $1990 \mathrm{~s}, 2050 \mathrm{~s}$, and 2090s in Hokkaido, Niigata, Aichi, and Kumamoto. The heading period was a 4-week period centering on the heading date, which occurs from the end of July to the middle of 
Table 3 Statistics of projected 20-year mean yield changes for four prefectures in the 2050s and 2090s, relative to the 1990s

\begin{tabular}{llccccc}
\hline Prefecture & Period & Mean $(\%)$ & SD $(\%)$ & P5 $(\%)$ & P50 (\%) & P95 (\%) \\
\hline Hokkaido & $2050 \mathrm{~s}$ & 17.2 & 14.1 & -5.2 & 17.3 & 40.3 \\
\multirow{4}{*}{ Niigata } & $2090 \mathrm{~s}$ & 26.9 & 14.3 & 6.3 & 26.1 & 51.2 \\
\multirow{3}{*}{ Aichi } & $2050 \mathrm{~s}$ & 4.6 & 8.1 & -9.4 & 4.7 & 17.3 \\
& $2090 \mathrm{~s}$ & 7.4 & 8.6 & -5.8 & 7.0 & 22.0 \\
\multirow{2}{*}{ Kumamoto } & $2050 \mathrm{~s}$ & 2.2 & 11.0 & -15.0 & 3.8 & 14.9 \\
& $2090 \mathrm{~s}$ & -0.8 & 16.8 & -33.4 & 2.8 & 17.9 \\
& $2050 \mathrm{~s}$ & 4.6 & 8.7 & -10.9 & 5.4 & 17.0 \\
& $2090 \mathrm{~s}$ & 6.4 & 11.8 & -15.6 & 8.0 & 22.8 \\
\hline
\end{tabular}

$S D$ standard deviation, P5 5\%-tile, P50 median, P95 95\%-tile

August in Japan. The number of extremely hot days was projected to increase over time in all prefectures. The increase is not very large in Hokkaido and Niigata, but it is remarkable in Aichi and Kumamoto. The increase in the number of extremely hot days and anticipated spikelet sterility caused by heat stress were the reasons for the extension of the tail of the PDFs to a negatively strong side in Aichi and Kumamoto (Fig. 6c and d).
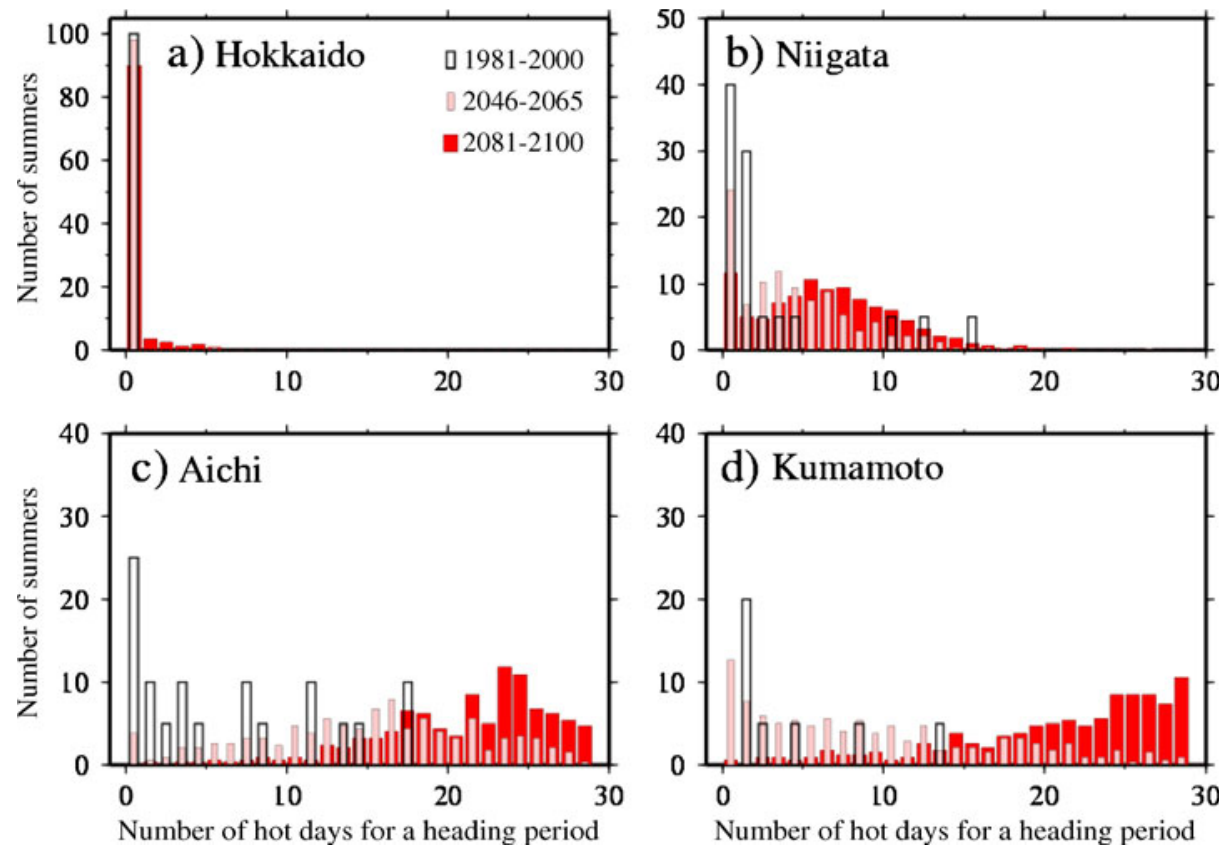

Fig. 7 Histograms of extremely hot days during a flowering period $\left(T_{\max }>33^{\circ} \mathrm{C}\right)$ observed in the 1990 s and projected for the 2050s and 2090s for four representative prefectures. The number of data is normalized to represent 100 summers in each histogram 


\subsection{Spatial change of paddy rice yield}

Figure 8 shows the probability maps of a decreasing 20 -year mean paddy rice yield and an increasing SD of yield for 20 years in the 2050s and 2090s, relative to the 1990s mean value, on a prefectural level. The probability of each of these negative impacts was computed from 850 simulation results (=17 climate projections based on 2 emission scenarios $\times 50$ sets of parameters) after calculating the mean and $\mathrm{SD}$ of the simulated yield for 20 years under both the current and future periods. The resulting probability maps indicate that the probabilities of a decreasing 20 -year mean yield during the 2050s and 2090s were both less than $10 \%$ in many prefectures in the northern part of Japan (Fig. $8 \mathrm{a}$ and b). The probability in the 2050s largely

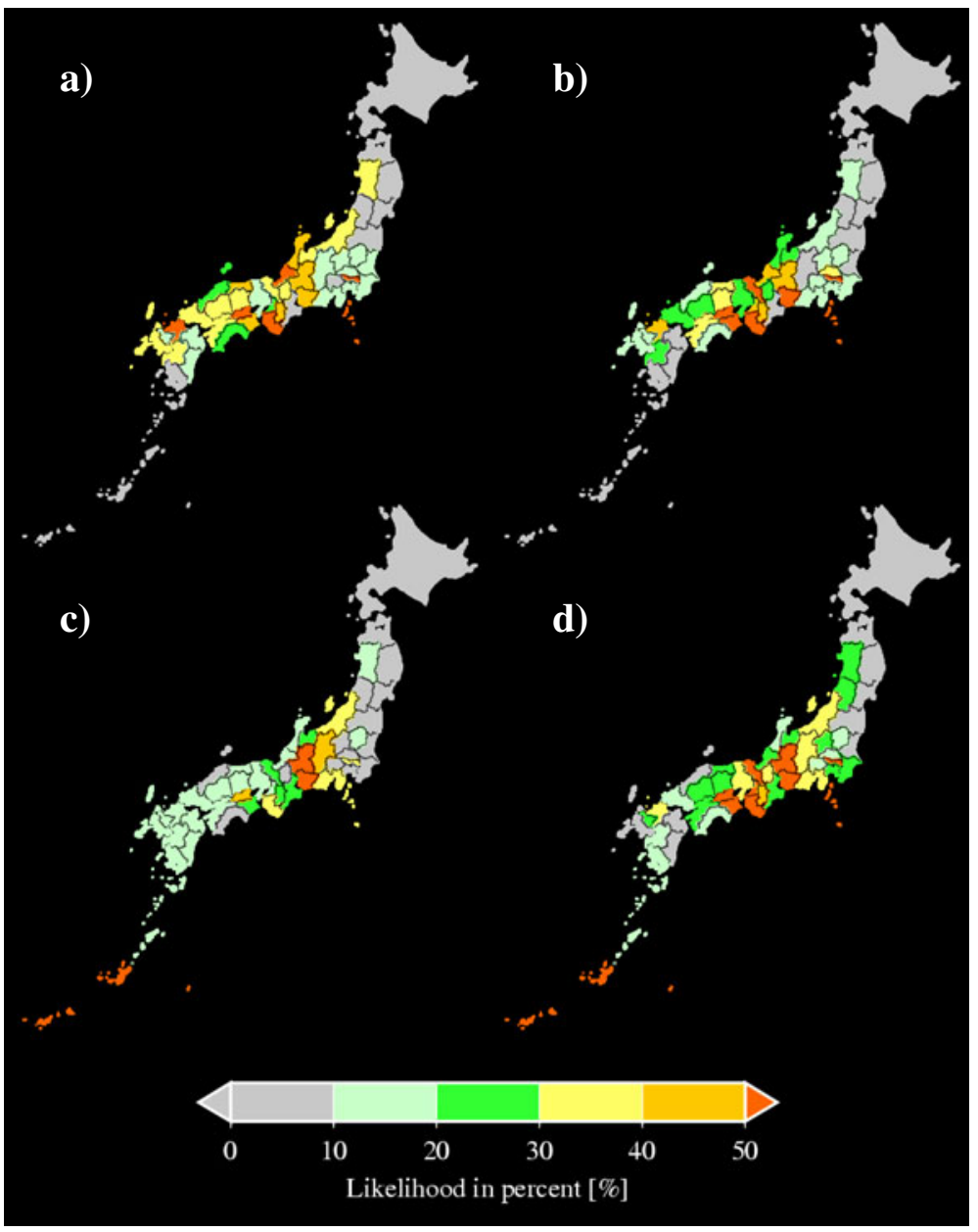

Fig. 8 Geographical maps of the probability that the 20-year mean paddy rice yield in the 2050s (a) and 2090s (b) will decrease, relative to the mean yield in the 1900s, and the probability that the standard deviation of yield in the 2050s (c) and 2090s (d) will increase relative to that in the 1990s 
varied by prefecture in the central and western parts of Japan, and that in the 2090s decreased in these areas except for several prefectures around Aichi. These results were in good agreement with the shifts of the PDFs, as shown in Fig. 6.

Meanwhile, the probability maps also indicate that the probabilities of an increasing SD of yield for 20 years in the 2050s and 2090s were both less than $10 \%$ in the northern and eastern parts of Japan except for the Sea of Japan side of these areas (Fig. 8c and d). The probability in the 2050s varied by prefecture in the central and western parts of Japan, and it increased over time in these areas. Particularly, the increase in probability was noticeable in the Pacific side of the central part of Japan (around Aichi).

Figure 9 presents the maps of the probability that future yield loss in a year induced by heat stress in the 2050s and 2090s will exceed the severest yield loss observed in the 1990s. Each PDF of extreme yield loss was computed from the 17,000 simulation results ( $=17$ climate projections based on 2 emission scenarios $\times 50$ sets of parameters $\times 20$ years). In practice, we counted the number of years if the simulated future yield in a year is below the observed minimum yield in the 1990s. The counted number of years is then normalized by the total sample size (i.e., 17,000). Almost all of the severest yield loss was observed in 1993 (see Fig. 4) and was caused by cool-summer damage in the northern part of Japan and the combination of insufficient sunshine and a typhoon in the western part of Japan. The probabilities of experiencing extremely severe yield loss in the 2050s and 2090s were both low ( $p \leq$ $1 \%$ ) in the northern part of Japan (Fig. 9a and b). The probability in the 2050s varied by prefecture in the central and western parts of Japan $(1 \%<p \leq 20 \%)$. However,

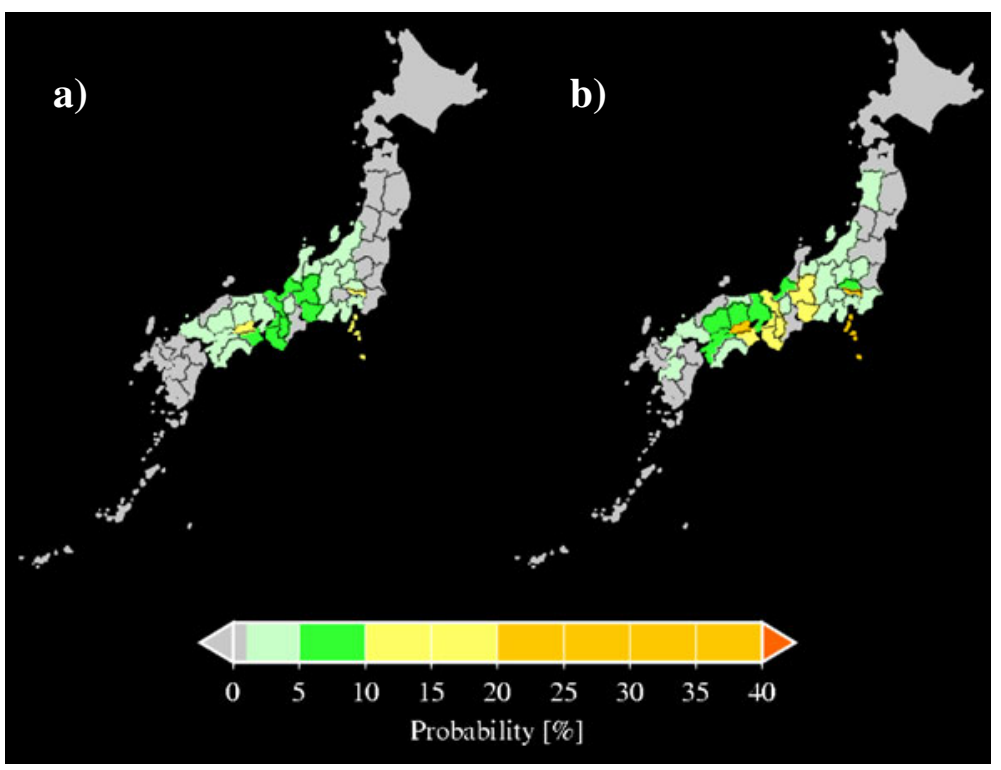

Fig. 9 Geographical maps of the probability that the yield loss induced by extremely hot conditions during the flowering period in the 2050s (a) and 2090s (b) will exceed the severest yield loss in the 1990s 
the probability increased over time in these areas. Particularly, the probability of $p>50 \%$ was found in the Pacific side of the central part of Japan (around Aichi).

\subsection{Relative contributions to uncertainty in projecting yield change}

Figure 10 presents the relative contributions of various factors (i.e., emission scenarios, GCMs, and crop parameter values) to the uncertainty in projecting paddy rice yield change in Hokkaido, Niigata, Aichi, and Kumamoto. The following three pairs of CDFs of yield changes were provided for each of the prefectures after eliminating MIROC3.2-HIRES data, since this GCM has no climate projection under the A2 scenario: (1) a pair of CDFs made from six common GCMs and 50 sets of parameter values but different emissions; (2) that made from two common emissions and 50
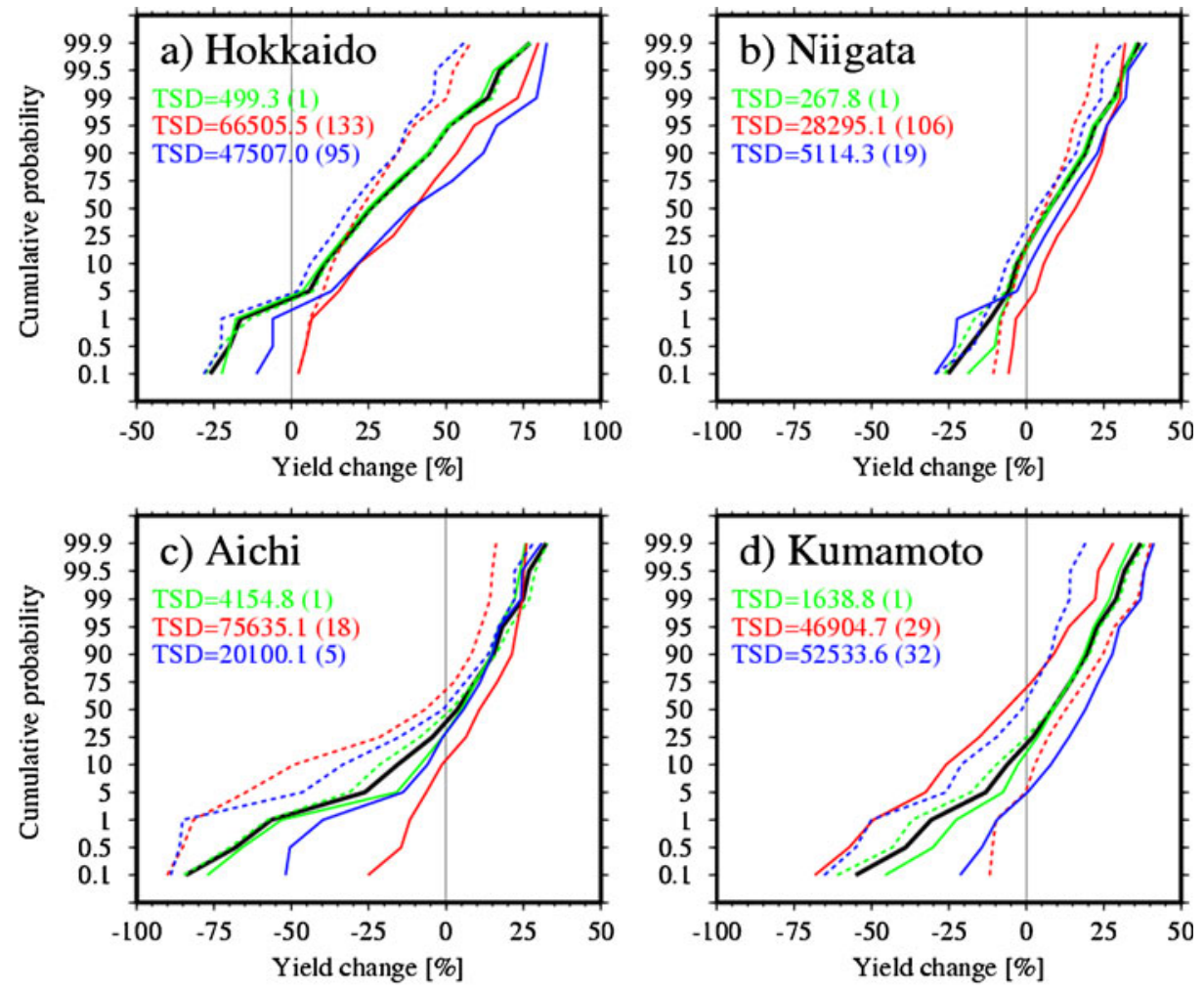

Common $6 \mathrm{GCMs}$ and 50 sets of parameters with different emission

Common 2 emissions and 50 sets of parameters with different GCM

Common 2 emissions and 6 GCMs with different set of parameters

2 emissions, $6 \mathrm{GCMs}$, and 50 sets of parameters

Fig. 10 Cumulative probability density functions of projected yield changes in the 2090s on the basis of different emission scenarios, different GCMs, and different sets of crop parameter values for four representative prefectures. TSD denotes the total squared difference between a pair of CDFs (indicated as solid and dashed line). The value in parentheses indicates the TSD value relative to that for the emission scenario 
sets of parameter values but different GCMs; and (3) that made from two common emissions and six GCMs but different sets of parameter values. Separately, the reference CDF was provided from the whole data. The sample size was 8,000 for case 1 (=8 climate projections with 1 emission $\times 50$ sets of parameter values $\times 20$ years); 2,000 for case $2(=2$ climate projections with 2 emissions $\times 50$ sets of parameter values $\times 20$ years); and 320 for case 3 (=16 climate projections under 2 emissions $\times 1$ set of parameter values $\times 20$ years). The number of data to draw CDFs was normalized to be the same as the smallest one (i.e., 320).

We calculated the total squared difference (TSD), given by the following equation, to quantify the relative contribution of each factor to the uncertainty in projecting yield change,

$$
T S D=\int_{-100}^{+100}\left[F_{1}(y)-F_{2}(y)\right]^{2} d y,
$$

where $F_{1}(y)$ and $F_{2}(y)$ denote the pair of CDFs mentioned above. We examined all possible pairs of GCMs ( $64=8 \times 8$ climate projections) for case 2 and drew the CDFs with the largest TSD in Fig. 10. The CDFs for case 3 was drawn in the same manner but from the possible pairs of sets of parameter values $(2500=50 \times 50$ sets of parameter values).

In Hokkaido, for instance, the TSD for case 2 (GCM) and case 3 (parameter values) is 133 times and 95 times larger than that for case 1 (emission), respectively (Fig. 10a). The TSD for case 2 (GCM) and case 3 (parameter values) is always larger than that for case 1 (emission) in all prefectures. In 3/4 of all prefectures, the TSD for case 2 (GCM) is the largest. Furthermore, the CDFs show a parallel shift regardless of the factors in Hokkaido and Niigata. Contrastively, for case 2 (GCM) and case 3 (parameter values) in Aichi and Kumamoto, the resulting change in CDFs is not a parallel shift, rather, a significant extension of the tail to a more negatively strong side. This areal difference in the CDF shift is caused by the combination of high temperature conditions during a flowering period and a $C_{h o t}$ value that represents the sensitivity of spikelet sterility under high temperature conditions (see Table 1). The occurrence of a spatial difference in terms of the contribution of the climate and crop parameter values to the projected yield change has been reported by Challinor et al. $(2005,2009)$. These results can be interpreted to mean that the choice of GCM is the primary reason for providing the range of projected yield change in many prefectures and the choice of parameter values could be a more important factor in a specific prefecture. Choosing the emission scenario shows a smaller contribution to the uncertainty in projecting yield change than the other factors in this study. However, the inclusion of the B1 scenario, which shows the lowest atmospheric $\mathrm{CO}_{2}$ concentration at the end of twenty-first century, could lead to different results.

\section{Discussion}

\subsection{Climate change and paddy rice yield in Japan}

Under warmer climate conditions, a shortening of the growing period (i.e., from transplanting to maturity) is recognized as a factor for decreasing paddy rice yield 
in Japan (Toritani et al. 1999; Iizumi et al. 2006, 2008). As temperatures rise, growth and development occur more rapidly, and the accumulated solar radiation is reduced during the growing period, resulting in a reduction in rice yield. In turn, our simulation results indicated a shortening of the growing period (Fig. 5). A yield decrease is expected following the simulated shortening of the growing period. However, contrary to our expectations, the resulting PDFs showed an increase in the 20-year mean yield in many cases (Fig. 6). These results must be carefully interpreted.

One major reason for the yield increase in our simulations is the drastic decrease in the frequency and intensity of cool-summer damage, which is a major cause of severe yield loss, especially in northern Japan. Insufficient solar radiation during a cool summer also contributes to yield loss in central and western Japan. The yield loss attributed to cool-summer damage is much larger than the gradual reduction in yield caused by the shorter growing period. Using the 20 -year mean yield, the reduction in yield caused by cool-summer damage cancels out the gradual reduction in yield caused by the shorter growing period and leads to the yield increase. The effects of $\mathrm{CO}_{2}$ fertilization on yield were included in the simulations, but the increase in the simulated yield induced by the increase in the concentration of atmospheric $\mathrm{CO}_{2}$ is not large enough to cancel out the reduction in yield caused by the shorter growing period, although the effect of $\mathrm{CO}_{2}$ fertilization contributes to offset some of the yield decrease. The assumption of no water stress in the future also contributes to this result.

A drastic reduction in yield caused by heat stress during a flowering period is the major concern during warming conditions in Japan (Horie et al. 1995b; Kim et al. 1996; Nakagawa et al. 2003). The drastic increase in the probability of extremely hot days, as suggested by Battisti and Naylor (2009), is also found in our model simulations (Fig. 7). However, the simulated heat stress induced by extremely hot days contributes little to the decrease in the 20-year mean yield and significantly to the increase in the interannual variation of yield in central to western Japan (Fig. 8c and $\mathrm{d}$ ). This is because the simultaneous occurrence of extremely hot days and flowering events is rare under the limited sample size of the 17 climate projections and the simulated yield is on almost the same level as the current yield with good harvest if the rice crop is not exposed to extremely hot weather. As described in Section 3.2, the $90 \%$ interval of yield changes includes several cases of yield reductions in central and western Japan. A larger sample of climate projections could provide a more simultaneous occurrence and could lead to a decrease in the 20-year mean.

From the viewpoint of the interannual variation of yield, a higher probability of increasing the SD of yield appears in central Japan (around Aichi). This is related to the planting window in this area. The planting window in this area is 1 month later than that in the neighboring prefectures. The simulated flowering date, thus, often occurs in midsummer (August), and extremely hot conditions occur more frequently than they do in the neighboring prefectures. In contrast, in northern Japan (e.g., Hokkaido), the frequency and intensity of cool-summer damage decrease. In addition, the occurrence of heat stress is very rare in that area even in the 2090s. This is compatible with the findings of Iizumi et al. (2007). As a result, the SD of yield in the northern part of Japan decreases, suggesting a more stabilized condition for paddy rice production. Furthermore, a few extremely hot days occur in the simulation results in Hokkaido (Fig. 7a). The potential risk of heat stress exists even in northern Japan, and the risk increases over time. 
4.2 Advantage of the ensemble-based projection approach

Uncertainties pose challenges and obstacles in the application of projected impacts on the development of adaptation strategies. The projected changes in long-term mean paddy rice yield in Japan have a wide-range spectrum depending on the emission scenario, GCM, and crop model used. We summarize the projected yield changes available from the literature in Fig. 11 and compared them to those from our results. The following four studies were used as examples:

(1) Seino (1995) uses three GCMs (GISS, GFDL, and UKMO) at the time of IPCC FAR with a $2 \times \mathrm{CO}_{2}$ scenario and a single-crop model (CERES-Rice). The projected yield change at the end of the twenty-first century is $-1.0 \%, 4.3 \%$, and $1.1 \%$ with a range of $(-11.3 \%,+7.2 \%),(-5.2 \%,+11.8 \%)$, and $(-2.5 \%$, $+6.0 \%$ ), relative to the 1980-1988 mean yield, in Miyagi (south of Hokkaido), Niigata, and Miyazaki (neighboring Kumamoto), respectively;

(2) The yield change at the end of the twenty-first century projected by Horie et al. $(1995 \mathrm{~b})$ is $+10 \%,+9.6 \%,-12.4 \%$, and $0.8 \%$ with a range of $(-2.8 \%,+25.5 \%)$, $(-10.5 \%,+25.1 \%),(-40.9 \%,-1.8 \%)$, and $(-10.0 \%,+7.8 \%)$, relative to the 1979-1990 mean yield, in Hokkaido, Toyama (neighboring Niigata), Aichi, and Miyazaki, respectively, on the basis of three GCMs (GISS, GFDL, and UKMO) that agree with those in Seino (1995) with two crop models (SIMRIW and ORYZA1);

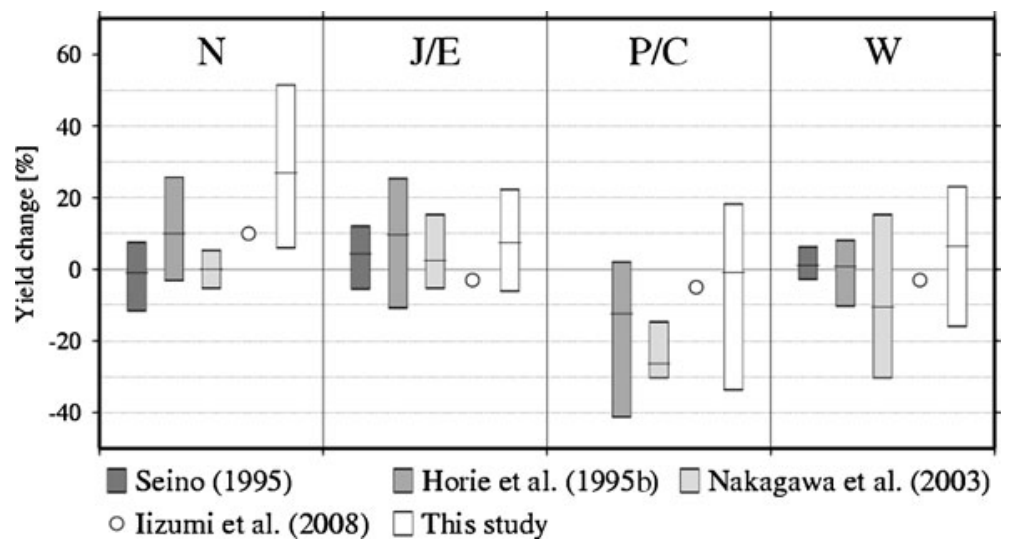

Fig. 11 Comparison of the projected yield change among studies for the northern area $(N)$, the Sea of Japan side of the eastern area $(J / E)$, the Pacific side of the central area $(P / C)$, and the western area $(W)$. For the four sources noted below, the upper and lower hinge of box indicates the maximum and minimum yield change, respectively. For this study, the box indicates a 90\% (5-95\%) interval. The line in a box indicates the mean value of data. Seino (1995) uses three GCMs at the time of IPCC FAR with a $2 \times \mathrm{CO}_{2}$ scenario with a single-crop model (CERES-Rice) (data for $\mathrm{P} / \mathrm{C}$ is not available); Horie et al. (1995b) uses three GCMs that are similar to those in Seino (1995) with two crop models (SIMRIW and ORYZA1); Nakagawa et al. (2003) uses four GCMs at the time of IPCC SAR with the IS92 scenario and a single-crop model (SIMRIW); Iizumi et al. (2008) uses a single GCM at the time of IPCC TAR with the SRES A2 scenario and a single-crop model (modified version of SIMRIW); and this study is based on over six GCMs at the time of IPCC AR4 with the SRES A1B and A2 scenario and a single-crop model (PRYSBI) with perturbation of the crop parameter values 
(3) Nakagawa et al. (2003) projected the yield change in the 10-year period (2090-2099) on the basis of four GCMs (CGCM1, CCSR/NIES, CSIRO-Mk2, and ECHAM/OPYC3) at the time of IPCC SAR with the IS92a scenario and a single-crop model (SIMRIW). The projected yield change is $+0 \%$, $+2.5 \%,-26.3 \%$, and $-10.6 \%$ with a range of $(-5 \%,+5 \%),(-5 \%,+15 \%)$, $(-30 \%,-15 \%)$, and $(-30 \%,+15 \%)$, relative to the $1971-2000$ mean yield, in Hokkaido, Niigata, Aichi, and Kumamoto, respectively;

(4) Iizumi et al. (2008) uses single GCM (MRI-CGCM2) with the SRES A2 scenario at the time of IPCC TAR and a single-crop model (a modified version of SIMRIW). The projected yield change in the $2070 \mathrm{~s}$ is $+10 \%,-8 \%,-5 \%$, and $-3 \%$, relative to the 1991-1999 mean yield, in Hokkaido, Niigata, Aichi, and Kumamoto, respectively.

The presented study projected the yield change in the 2090s (2081-2100) on the basis of over six GCMs (see Table 2) at the time of IPCC AR4 with SRES A1B and A2 scenarios and a single-crop model (PRYSBI) with the perturbation of crop parameter values. The projected yield change is $26.9 \%, 7.4 \%,-0.8 \%$, and $6.4 \%$ with a $90 \%$ interval of $(+6.3 \%,+51.2 \%),(-5.8 \%,+22.0 \%),(-33.4 \%,+17.9 \%)$, and $(-15.6 \%,+22.8 \%)$, relative to the 1981-2000 mean yield, in Hokkaido, Niigata, Aichi, and Kumamoto, respectively.

From these studies, we conclude that the projected direction of yield change (whether it increases or decreases in an intended area) is fairly consistent among studies but there is a large quantitative difference. Furthermore, the more recent studies (Nakagawa et al. 2003 and the present study) do not necessarily provide a smaller range of changes in the projected yield than that in previous studies (Seino 1995; Horie et al. 1995b). The range in the change of the projected yield in the present study is still large in comparison to those reported in previous studies. Three studies (Seino 1995; Horie et al. 1995b; Nakagawa et al. 2003) may underestimate the changes in the range of the projected yield, considering the situation in which the variety of emission scenarios and GCMs used is limited, and they only run crop model simulations at a specific site for a prefecture with climatological mean weather inputs. They, therefore, did not consider the effects of interannual variation of climate and spatial heterogeneity of crop production aspects in a prefecture on long-term mean yield. However, a more careful comparison is needed to conclude whether the continual progress in climate and crop modeling for the recent decades could narrow the range of the projected yield change. Nevertheless, the ensemblebased projection approach used here can provide an answer including a probability measure to the question of how much paddy rice yield will change in Japan, which is necessary information for stakeholders and policymakers to manage climate risks. This is the most significant advantage of the ensemble-based projection approach.

\subsection{Remaining uncertainties}

In this study, we examined the uncertainties of climate projections and crop parameter values into the projection of paddy rice yield changes in Japan. We used 17 climate projections performed by over six GCMs with two emission scenarios (SRES $\mathrm{A} 1 \mathrm{~B}$ and $\mathrm{A} 2$ ). The emission scenarios used cover the atmospheric $\mathrm{CO}_{2}$ concentration from $515.2 \mathrm{ppm}$ to $607.5 \mathrm{ppm}$ for the $2050 \mathrm{~s}$ and from $652.6 \mathrm{ppm}$ to $856.0 \mathrm{ppm}$ for the 2090s. However, our setting does not cover the whole range of SRES, since the 
most intensive and moderate $\mathrm{CO}_{2}$ concentration in the atmosphere appears in A1F1 and $\mathrm{B} 1$, respectively. The presented projection of yield change in this study is, thus, conditional on SRES A1B and A2.

The climate projections used cover almost all ranges of global surface warming under the two given emission scenarios among available GCMs. Global surface warming, relative to the $1990 \mathrm{~s}$, is from $1.0^{\circ} \mathrm{C}$ (CSIRO-Mk3.0) to $2.7^{\circ} \mathrm{C}$ (MIROC3.2HIRES) in the $2050 \mathrm{~s}$ and from $1.8^{\circ} \mathrm{C}$ (CSIRO-Mk3.0) to $4.1^{\circ} \mathrm{C}$ (MIROC3.2-HIRES) in the 2090s. The number of GCMs used is limited because we selected only the GCMs that were available in daily data for all three climatic elements (daily maximum and minimum temperatures and solar radiation). The use of a weather generator (e.g., Tao et al. 2008) may bring our ensemble-based projection to a more probabilistic one. In addition, the inclusion of the uncertainty in projecting a regional climate change associated with downscaling methods (e.g., Schmidli et al. 2006) is an area for further study.

The crop parameter values of the PRYSBI model used cover a wider range of parameter values in many cases than that of the specific cultivars (Fig. 2). However, in this study, we did not perturb the parameter values related to the effects of elevated $\mathrm{CO}_{2}$, such as the shortening of the growing period from emergence to heading and the change in radiation-use efficiency. The simulated spikelet sterility caused by heat stress is sensitive to the manner of modeling. The inclusion of multiple parameterizations of spikelet sterility induced by heat stress is needed for further improvement. In addition, recently, some studies (e.g., Tubiello et al. 2007; Tao et al. 2009a) suggest that the modeling of the $\mathrm{CO}_{2}$ fertilization effect is too simplified in many crop models and could be a source of uncertainty in projecting the impact of climate change on crop productivity. Improving the modeling in basic biophysical processes, including the $\mathrm{CO}_{2}$ fertilization effect, is important for further reduction of the uncertainty associated with crop models.

\section{Conclusions}

We used an ensemble-based projection approach and projected the climate change impacts on paddy rice yield in Japan, including the partial uncertainties of climate projections and crop parameter values. We provided the CDFs of projected yield changes in the 2050s and 2090s, relative to the 1990s mean yield, on the basis of many simulation results and provided information of future yield change with probability conditioned on the SRES A1B and A2 scenario. The ensemble-based projection approach provides information that stakeholders and policymakers consider more desirable for managing climate risks.

\section{Nomenclature}

AR4

CCSR/NIES
IPCC Fourth Assessment Report

global climate model of Center for Climate System Research (CCSR), University of Tokyo and National Institute for Environmental Studies (NIES) (Emori et al. 1999) 
CERES-Rice

CGCM1

CGCM3.1

CSIRO-Mk2

CSIRO-Mk3.0 (Mk3.5)

ECHAM4/OPYC3

FAR

GFDL

GFDL-CM2.0

GISS

IPCC

IS92a

MIROC3.2-MEDRES (HIRES)

MRI-CGCM2

MRI-CGCM2.3.2A

ORYZA1

SIMRIW

SAR

SRES

TAR
Crop Environment Resource Synthesis Model for Rice (Godwin et al. 1990)

The first generation of the coupled global climate model of Canadian Center for Climate Modeling and Analysis (CCCma) (Flato et al. 2000)

The third generation of the coupled global climate model of CCCma (Flato et al. 2000)

Australia's Commonwealth Scientific and Industrial Research Organization (CSIRO) Mk2 Climate System Model (Watterson et al. 1997)

CSIRO Mk3 (Mk3.5) Climate System Model (Gordon et al. 2002)

The coupled global climate model of the European Center for Medium-Range Weather Forecasts (ECMWF) and the Max Plank Institute for Meteorology (Roeckner et al. 1992; Oberhuber et al. 1998)

IPCC First Assessment Report (Houghton et al. 1990)

The Geophysical Fluid Dynamics Laboratory (GFDL)'s coupled global climate model (version 1) (Manabe and Wethetald 1986)

The GFDL's coupled global climate model (version 2.0) (Delworth et al. 2006)

The Goddard Institute for Space Studies (GISS) global climate model (Hansen et al. 1983)

Intergovernmental Panel on Climate Change

IPCC emission scenario (type a) (Leggett et al. 1992)

The Model for Interdisciplinary Research on Climate Medium (High) resolution version developed by CCSR, NIES, and the Frontier Research Center for Global Change (FRCGC) (K-1 model developers 2004)

The Meteorological Research Institute (MRI) Coupled General Circulation Model version 2 (Yukimoto et al. 2001)

The MRI Coupled General Circulation Model version 2.3.2a (Yukimoto and Noda 2002)

Crop model for rice (Kropef et al. 1995)

Simulation Model for Rice-Weather Relationships (Horie et al. 1995a)

IPCC Second Assessment Report (Houghton et al. 1995)

IPCC Special Report on Emission Scenarios (Nakicenovic and Swart 2000)

IPCC Third Assessment Report (Houghton et al. 2001) 
UKMO

The coupled global climate model of Hadley Center, UK Met Office (Wilson and Mitchell 1987)

Acknowledgements The IPCC Data Archive at the Lawrence Livermore National Laboratory is supported by the Office of Science, U.S. Department of Energy. We are grateful to the individuals at the CCSR for distributing the MIROC3.2-HIRES data. This study was supported by the Global Environmental Research Fund (S-4 and S-5-3) of the Ministry of the Environment, Japan.

Open Access This article is distributed under the terms of the Creative Commons Attribution Noncommercial License which permits any noncommercial use, distribution, and reproduction in any medium, provided the original author(s) and source are credited.

\section{References}

Battisti DS, Naylor RL (2009) Historical warnings of future food insecurity with unprecedented seasonal heat. Science 323:240-244

Carter TR, Alfsen K, Barrow E, Bass B, Dai X, Desanker P, Gaffin SR, Giorgi F, Hulme M, Lal M, Mata LJ, Mearns LO, Mitchell JFB, Morita T, Moss R, Murdiyarso D, Pabon-Caicedo JD, Palutikof J, Parry ML, Rosenzweig C, Seguin B, Scholes RJ, Whetton PH (2007) Guidelines on the use of scenario data for climate impact and adaptation assessment version 2. In: The directory of supporting material. The IPCC Data Distribution Center. http://www.ipcc-data. org/guidelines/. Accessed 13 Apr 2009

Challinor AJ, Wheeler TR (2008) Crop yield reduction in the tropics under climate change: processes and uncertainties. Agric For Meteorol 148:343-356

Challinor AJ, Wheeler TR, Slingo JM, Hemming D (2005) Quantification of physical and biological uncertainty in the simulation of the yield of a tropical crop using present day and doubled $\mathrm{CO}_{2}$ climates. Phil Trans Roy Soc B 360:1981-2194

Challinor AJ, Wheeler TR, Hemming D, Upadhyaya HD (2009) Ensemble yield simulations: crop and climate uncertainties, sensitivity to temperature and genotypic adaptation to climate change. Clim Res 38:117-127

Delworth TL, Broccoli AJ, Rosati A, Stouffer RJ, Balaji V, Beesley JA, Cooke WF, Dixon KW, Dunne J, Dunne KA, Durachta JW, Findell KL, Ginoux P, Gnanadesikan A, Gordon CT, Griffies SM, Gudgel R, Harrison MJ, Held IM, Hemler RS, Horowitz LW, Klein SA, Knutson TR, Kushner PJ, Langenhorst AR, Lee HC, Lin SJ, Lu J, Malyshev SL, Milly PCD, Ramaswamy V, Russell J, Schwarzkopf MD, Shevliakova E, Sirutis JJ, Spelman MJ, Stern WF, Winton M, Wittenberg AT, Wyman B, Zeng F, Zhang R (2006) GFDL's CM2 global coupled climate models-part 1: formulation and simulation characteristics. J Clim 19:643-674

Easterling WE, Aggarwal PK, Batima P, Brander KM, Erda L, Howden SM, Kirilenko A, Morton J, Soussana J-F, Schmidhuber J, Tubiello FN (2007) Food, fiber and forest products. In: Parry ML, Canziani OF, Palutikof JP, van der Linden PJ, Hanson CE (eds) Climate change 2007: impacts, adaptation and vulnerability. Contribution of working group II to the fourth assessment report of the intergovernmental panel on climate change. Cambridge University Press, Cambridge, pp 273-313

Emori S, Nozawa T, Abe-Ouchi A, Numaguti A, Kimoto M, Nakajima T (1999) Coupled oceanatmosphere model experiments of future climate change with an explicit representation of sulfate aerosol scattering. J Meteorol Soc Jpn 77:1299-1307

Flato GM, Boer GJ, Lee WG, McFarlane NA, Ramsden D, Reader MC, Weaver AJ (2000) The Canadian center for climate modeling and analysis global coupled model and its climate. Clim Dyn 16:451-467

Geman S, Geman D, Abend K, Harley TJ, Kanal LN (1993) Stochastic relaxation: Gibbs distributions and the Bayesian restoration of images. J Appl Stat 20:25-62

Geographical Survey Institute (GSI) (1998) User's guide for numerical map, revised 2nd edn. Japan Map Center, Tokyo

Godwin DC, Singh U, Buresh RT, DeDatta SK (1990) Modeling of nitrogen dynamics in relation to rice growth and yield. In: 14th International soil science congress, IV-320-325, Aug. 1990, Kyoto, Japan 
Gordon HB, Rotstayn LD, McGregor JL, Dix MR, Kowalczyk EA, O'Farrell SP, Waterman LJ, Hirst AC, Wilson SG, Collier MA, Watterson IG, Elliott TI (2002) The CSIRO Mk3 climate system model. CSIRO Atmospheric Research Technical Paper 60, p 130

Hansen J, Russell G, Rind D, Stone P, Lacis A, Lebedeff S, Ruedy R, Travis L (1983) Efficient three-dimensional global models for climate studies: models I and II. Mon Weather Rev 3:609662

Horie T, Nakagawa H, Centeno HGS, Kropff MJ (1995a) The rice crop simulation model SIMRIW and its testing. In: Matthews RB, Kropff MJ, Bachelet D (eds) Modeling the impact of climate change on rice production in Asia. IRRI and CAB International, pp 51-66

Horie T, Nakagawa H, Ohnishi M, Nakano J (1995b) Rice production in Japan under current and future climates. In: Matthews RB, Kropff MJ, Bachelet D (eds) Modeling the impact of climate change on rice production in Asia. IRRI and CAB International, pp 143-164

Houghton JT, Jenkins GJ, Ephraums JJ (1990) Climate change: the IPCC scientific assessment. Contribution of working group I to the first assessment report of the intergovernmental panel on climate change. Cambridge University Press, New York, p 365

Houghton JT, Meira Filho LG, Callander BA, Harris N, Kattenberg A, Maskell K (1995) Climate change 1995: the science of climate change. Contribution of working group I to the second assessment report of the intergovernmental panel on climate change. Cambridge University Press, New York, p 572

Houghton JT, Ding Y, Griggs DJ, Noguer M, van der Linden PJ, Dai X, Maskell K, Johnson CA (2001) Climate change 2001: the scientific basis. Contribution of working group I to the third assessment report of the intergovernmental panel on climate change. Cambridge University Press, Cambridge, p 881

Iizumi T, Hori ME, Yokozawa M, Nakagawa H, Hayashi Y, Kimura F (2006) Impact of global warming on rice production in Japan based on five coupled atmosphere-ocean GCMs. SOLA 2:156-159

Iizumi T, Hayashi Y, Kimura F (2007) Influence on rice production in Japan from cool and hot summers after global warming. J Agric Meteorol 63:11-23

Iizumi T, Yokozawa M, Hayashi Y, Kimura F (2008) Climate change impact on rice insurance payouts in Japan. J Appl Meteorol Climatol 47:2265-2278

Iizumi T, Yokozawa M, Nishimori M (2009) Parameter estimation and uncertainty analysis of a large-scale crop model for paddy rice: application of a Bayesian approach. Agric For Meteorol 149:333-348

Katz RW (2002) Techniques for estimating uncertainty in climate change scenarios and impact studies. Clim Res 20:167-185

Kim H, Horie T, Nakagawa H, Wada K (1996) Effects of elevated $\mathrm{CO}_{2}$ concentration and high temperature on growth and yield of rice: I. The effect on development, dry matter production and some growth characteristics. Japan J Crop Sci 65:634-643

Kimoto M, Yasutomi N, Yokoyama C, Emori S (2005) Projected changes in precipitation characteristics around Japan under the global warming. SOLA 1:85-88

Kropef MJ, Matthews RB, van Laar HH, ten Berge HFM (1995) The rice model ORYZA1 and its testing. In: Matthews RB, Kropff MJ, Bachelet D (eds) Modeling the impact of climate change on rice production in Asia. IRRI and CAB International, pp 27-50

Kurihara K, Ishihara K, Sasaki H, Fukuyama Y, Saitou H, Takayabu I, Murazaki K, Sato Y, Yukimoto S, Noda A (2005) Projection of climatic change over Japan due to global warming by high-resolution regional climate model in MRI. SOLA 1:97-100

K-1 model developers (2004) K-1 coupled GCM (MIROC) description. In: Hasumi H, Emori S (eds) K-1 tech report 1. Center for Climate System Research, Tokyo, pp 1-39

Leggett J, Pepper WJ, Swart RJ (1992) Emissions scenarios for the IPCC: an update. Climate change 1992, The supplementary report to the IPCC scientific assessment. Cambridge University Press, Cambridge, pp 68-95

Lobell DB, Burke MB (2008) Why are agricultural impacts of climate change so uncertain? The importance of temperature relative to precipitation. Environ Res Lett. doi:10.1088/17489326/3/3/034007

Manabe S, Wethetald RT (1986) Reduction in summer soil wetness induced by an increase in atmospheric carbon dioxide. Science 232:626-628

Meehl GA, Stocker TF, Collins WD, Friedlingstein P, Gaye AT, Gregory JM, Kitoh A, Knutti R, Murphy JM, Noda A, Raper SCB, Watterson IG, Weaver AJ, Zhao Z-C (2007a) Global climate projections. In: Solomon S, Qin D, Manning M, Chen Z, Marquis M, Averyt KB, Tignor M, Miller HL (eds) Climate change 2007: the physical science basis. Contribution of working group 
I to the fourth assessment report of the intergovernmental panel on climate change. Cambridge University Press, Cambridge, pp 747-845

Meehl GA, Covey C, Delworth T, Latif M, McAvaney B, Mitchell JFB, Stouffer RJ, Taylor KE (2007b) The WCRP CMIP3 multimodel dataset: a new era in climate change research. Bull Am Meteorol Soc 88:1383-1394

Ministry of Agriculture, Forestry and Fisheries (MAFF) (1998) A new method for calculating decare standard yield of paddy rice in Japan. Association of Agriculture and Forestry Statistics, Tokyo (in Japanese)

Murphy JM, Sexton DMH, Barnett DN, Jones GS, Webb MJ, Collins M, Stainforth DA (2004) Quantification of modeling uncertainties in a large ensemble of climate change simulations. Nature 430:768-772

Nakagawa H, Horie T, Matsui T (2003) Effects of climate change on rice production and adaptive technologies. In: Mew TW, Brar DS, Peng S, Dawe D, Hardy B (eds) Rice science: innovations and impact for livelihood. IRRI and Chinese Academy of Engineering and Chinese Academy of Agricultural Sciences, pp 635-658

Nakicenovic N, Swart R (2000) Special report on emissions scenarios: a special report of working group III of the intergovernmental panel on climate change. Cambridge University Press, Cambridge, p 612

Oberhuber JM, Roeckner E, Christoph M, Esch M, Latif M (1998) Predicting the '97 E1 Nino event with a global climate model. Geophys Res Lett 25:2273-2276

Okada M, Iizumi T, Nishimori M, Yokozawa M (2009) Mesh climate change data of Japan ver.2 for assessing climate change impacts under IPCC SRES A1B and A2. J Agric Meteorol 65:97-109

Parry ML, Rosenzweig C, Iglesias A, Livermore M, Fischer G (2004) Effects of climate change on global food production under SRES emissions and socio-economic scenarios. Glob Environ Change 14:53-67

Roeckner E, Arpe K, Bengtsson L, Brinkop S, Dumenil L, Esch M, Kirk E, Lunkeit F, Ponater M, Rockel B, Suasen R, Schlese U, Schubert S, Windelband M (1992) Simulation of the present-day climate with the ECHAM4 model: impact of model physics and resolution. Max Planck Institute for Meteorology, Report No. 93, Hamburg, p 171

Schmidli J, Frei C, Vidale PL (2006) Downscaling from GCM precipitation: a benchmark for dynamical and statistical downscaling methods. Int J Climatol 26:679-689

Seino H (1993) An estimation of distribution of meteorological elements using GIS and AMeDAS data. J Agric Meteorol 48:379-383

Seino H (1995) The impacts of climate warming on cereal crop production in Japan. J Agric Meteorol 51:131-138

Tao F, Hayashi Y, Zhang Z, Sakamoto T, Yokozawa M (2008) Global warming, rice production, and water use in China: developing a probabilistic assessment. Agric For Meteorol 148:94-110

Tao F, Yokozawa M, Zhang Z (2009a) Modeling the impacts of weather and climate variability on crop productivity over a large area: a new process-based model development, optimization, and uncertainties analysis. Agric For Meteorol 149:831-850

Tao F, Zhang Z, Liu J, Yokozawa M (2009b) Modeling the impacts of weather and climate variability on crop productivity over a large area: a new super-ensemble based probability projection. Agric For Meteorol 149:1266-1278

Toritani H, Yonemura S, Yokozawa M (1999) Potential rice yield in the 21st century in Japan under the climate change scenario based on MRI-CGCM. J Japan Agric Syst Soc 15:8-16

Tubiello FN, Amthor JS, Boote KJ, Donatelli M, Easterling W, Fischer G, Gifford RM, Howden M, Reilly J, Rosenzweig C (2007) Crop response to elevated $\mathrm{CO}_{2}$ and world food supply: a comment on 'Food for Thought...' by Long et al. Science 312:1918-1921, 2006. Eur J Agron 26:215-223

Watterson IG, O'Farrell SP, Dix MR (1997) Energy and water transport in climates simulated by a general circulation model that includes dynamic sea ice. J Geophys Res 102(D10), 11,027-11,037

Wilson CA, Mitchell JFB (1987) A doubled $\mathrm{CO}_{2}$ climate sensitivity experiment with a global climate model including a simple ocean. J Geophys Res 92, D11. doi:10.1029/JD092iD11p13315

Yokozawa M, Iizumi T, Okada M (2009) Large scale projection of climate change impacts on variability in rice yield in Japan. Glob Environ Res 14:199-206 (in Japanese)

Yukimoto S, Noda A (2002) Improvements of the meteorological research institute global oceanatmosphere coupled GCM (MRI-CGCM2) and its climate sensitivity. Center Glob Environ Res (CGER)'s Super Computer Activity Report 10:37-44

Yukimoto S, Noda A, Kitoh A, Sugi M, Kitamura Y, Hosaka M, Shibata K, Maeda S, Uchiyama T (2001) A new meteorological research institute coupled GCM (MRI-CGCM2): its climate and variability. Pap Meteorol Geophys 51:47-88 